\title{
Hand Foot and Mouth Disease
}

National Cancer Institute

\section{Source}

National Cancer Institute. Hand Foot and Mouth Disease. NCI Thesaurus. Code C128439.

A clinical syndrome that is usually caused by enterovirus infection, and that is characterized by fever, anorexia, and painful sores in the mouth, distal extremities, and/or other sites, including the buttocks. 